\title{
Mechanical properties of hot-pressed high-entropy diboride-based ceramics
}

\author{
Ji-Xuan LIU, Xiao-Qin SHEN, Yue WU, Fei LI, \\ Yongcheng LIANG, Guo-Jun ZHANG ${ }^{*}$

\begin{abstract}
State Key Laboratory for Modification of Chemical Fibers and Polymer Materials, College of Materials Science and Engineering, College of Sciences, Institute of Functional Materials, Donghua University, Shanghai 201620, China
\end{abstract}

Received: February 22, 2020; Revised: April 30, 2020; Accepted: May 1, 2020

(C) The Author(s) 2020.

\begin{abstract}
High-entropy ceramics attract more and more attention in recent years. However, mechanical properties especially strength and fracture toughness for high-entropy ceramics and their composites have not been comprehensively reported. In this work, high-entropy $\left(\mathrm{Ti}_{0.2} \mathrm{Zr}_{0.2} \mathrm{Hf}_{0.2} \mathrm{Nb}_{0.2} \mathrm{Ta}_{0.2}\right) \mathrm{B}_{2}(\mathrm{HEB})$ monolithic and its composite containing $20 \mathrm{vol} \% \mathrm{SiC}$ (HEB-20SiC) are prepared by hot pressing. The addition of $\mathrm{SiC}$ not only accelerates the densification process but also refines the microstructure of HEB, resulting in improved mechanical properties. The obtained dense HEB and HEB-20SiC ceramics hot pressed at $1800{ }^{\circ} \mathrm{C}$ exhibit four-point flexural strength of $339 \pm 17 \mathrm{MPa}$ and $447 \pm 45 \mathrm{MPa}$, and fracture toughness of $3.81 \pm 0.40 \mathrm{MPa} \cdot \mathrm{m}^{1 / 2}$ and $4.85 \pm 0.33 \mathrm{MPa} \cdot \mathrm{m}^{1 / 2}$ measured by single-edge notched beam (SENB) technique. Crack deflection and branching by $\mathrm{SiC}$ particles is considered to be the main toughening mechanisms for the HEB-20SiC composite. The hardness $H v_{0.2}$ of the sintered HEB and HEB-20SiC ceramics is $23.7 \pm 0.7 \mathrm{GPa}$ and $24.8 \pm 1.2 \mathrm{GPa}$, respectively. With the increase of indentation load, the hardness of the sintered ceramics decreases rapidly until the load reaches about $49 \mathrm{~N}$, due to the indentation size effect. Based on the current experimental investigation it can be seen that the room temperature bending strength and fracture toughness of the high-entropy diboride ceramics are within ranges commonly observed in structure ceramics.
\end{abstract}

Keywords: high-entropy ceramics; high-entropy diboride; flexural strength; fracture toughness; indentation size effect

\section{Introduction}

Entropy is an important thermodynamic parameter of a matter. Usually, high-entropy causes low Gibbs free energy and consequently results in high thermal stability

\footnotetext{
* Corresponding author.

E-mail: gjzhang@dhu.edu.cn
}

of the materials thermodynamically. Based on this principle, a new group of materials-high-entropy materials with equimolar or near-equimolar proportions of five or more elements have been developed in recent years [1,2]. A number of high-entropy ceramic materials have been reported, including high-entropy borides [3-8], high-entropy carbides [9-12], high-entropy oxides [13-16], high-entropy silicides [17,18], high-entropy fluoride [19], as well as high-entropy metal oxycarbonitride 
[20]. After the first report by Gild et al. [3] in 2016 on the high-entropy diboride ceramics, much attentions have been attracted on the preparation and characterization of this material, including synthesis [3-8], densification by spark plasma sintering (SPS) [3-6], and microstructure tailoring $[5,8]$.

Mechanical properties are important references for the engineering design and application of a material. Recently we reported the mechanical properties including flexural strength and fracture toughness of $\left(\mathrm{Ti}_{0.2} \mathrm{Zr}_{0.2} \mathrm{Hf}_{0.2} \mathrm{Nb}_{0.2} \mathrm{Ta}_{0.2}\right) \mathrm{C}$ monolithic ceramics and its composite with the addition of $20 \mathrm{vol} \% \mathrm{SiC}$ secondary phase [12]. The results demonstrate that the values of bending strength and fracture toughness at room temperature are typical of structure ceramics. However, the mechanical properties of high-entropy diboride ceramics have not yet been extensively evaluated except for the Vickers hardness as well as fracture toughness by indentation technique [3-7]. It is reported that high-entropy diboride ceramics even with $\sim 8 \mathrm{vol} \%$ porosity exhibited higher hardness over the average of the corresponding five individual diboride ceramics [3]. For fracture toughness $\left(K_{\mathrm{IC}}\right)$, only a few open publications reported values measured by indentation technique and the values are very scattering [4-6]. As the fracture toughness is very sensitive to the measurement techniques, comparable study via different techniques for the evaluation of fracture toughness is meaningful. On the other hand, up to now there is no open report concerning the flexural strength of high-entropy diboride ceramics.

Very recently, we investigated the effects of sintering temperature and the addition of SiC secondary phase on the microstructure of high-entropy $\left(\mathrm{Ti}_{0.2} \mathrm{Zr}_{0.2} \mathrm{Hf}_{0.2^{-}}\right.$ $\left.\mathrm{Nb}_{0.2} \mathrm{Ta}_{0.2}\right) \mathrm{B}_{2}$ ceramics. The results indicate that the addition of $\mathrm{SiC}$ secondary particles can obviously inhibit the grain growth of $\left(\mathrm{Ti}_{0.2} \mathrm{Zr}_{0.2} \mathrm{Hf}_{0.2} \mathrm{Nb}_{0.2} \mathrm{Ta}_{0.2}\right) \mathrm{B}_{2}$ phase and refine the microstructure. However, limited by the sample size $(\varnothing 10 \mathrm{~mm} \times 5 \mathrm{~mm})$ prepared by our SPS equipment, only their hardness and fracture toughness were investigated by indentation method in our previous work [5]. In this study, firstly dense highentropy $\left(\mathrm{Ti}_{0.2} \mathrm{Zr}_{0.2} \mathrm{Hf}_{0.2} \mathrm{Nb}_{0.2} \mathrm{Ta}_{0.2}\right) \mathrm{B}_{2}$ (HEB) monolithic ceramics and its composite containing $20 \mathrm{vol} \% \mathrm{SiC}$ (HEB-20SiC) with dimensions of $37 \mathrm{~mm} \times 30 \mathrm{~mm} \times$ $5 \mathrm{~mm}$ are prepared by hot pressing. Then the mechanical properties including Young's modulus, bulk modulus, shear modulus, Poisson's ratio, Vickers hardness, four-point flexural strength, and fracture toughness by single-edge notched beam (SENB) technique are systematically investigated. The effect of $\mathrm{SiC}$ secondary phase on the microstructure evolution and mechanical properties of hot-pressed HEB ceramics is also discussed.

\section{Experimental procedure}

\section{1 Sample preparation}

The following process was used to prepare the diboride-based ceramics. The laboratory-synthesized high-entropy diboride powder with an average particle size of $1.4 \mu \mathrm{m}$ and residual oxygen content of $1.56 \mathrm{wt} \%$ was planetary ball milled without or with the addition of $20 \mathrm{vol} \% \alpha-\mathrm{SiC}$ powder $(>98.5 \%, \sim 0.45 \mu \mathrm{m})$ using WC balls as milling media (the ball milling process caused about $0.3 \mathrm{wt} \%$ loss of WC balls). Details of the synthesis process for the high-entropy diboride powder and the preparation of powder mixture for the HEB-20 vol\% $\mathrm{SiC}$ (HEB-20SiC) composite were reported in our previous publication [5]. The obtained powders were put in $\mathrm{BN}$ coated graphite mold and then hot pressed at $1800{ }^{\circ} \mathrm{C}$ for $1 \mathrm{~h}$ in an argon atmosphere (ZT-40-21Y, Shanghai Chen Hua Science and Technology Co. Ltd., China). The as-sintered samples were sectioned into bars followed by grinding and polishing to $0.5 \mu \mathrm{m}$ diamond paste. The four edges were beveled using 1500 grit diamond disk.

\section{2 Sample characterization}

The densities of the sintered samples were measured by Archimedes method. To evaluate the relative density (R.D.) of the sintered samples, the theoretical density of HEB was calculated according to its lattice constants. The phase composition of the sintered samples as well as the crystalline cell parameters were studied by X-ray diffraction (XRD, D/max-2550VB+/PC, Rigaku Corp., Tokyo, Japan) with $\mathrm{Cu} \mathrm{K} \alpha$ radiation using $\mathrm{Si}$ as an internal standard. Field emission scanning electron microscope (FE-SEM, S-4800, Hitachi High-technologies Corp., Tokyo, Japan) equipped with energy dispersive spectroscopy (EDS) was used for analyzing the microstructures of the sintered samples.

According to ASTM standard C1161-18, four-point flexural strength $(\sigma)$ of the sintered ceramics was measured by Shimadzu universal testing machine (AGS-X, Shimadzu Corp., Tokyo, Japan) using type A bars with dimensions of $1.5 \mathrm{~mm} \times 2 \mathrm{~mm} \times 25 \mathrm{~mm}$. The 
inner and outer spans used for the testing were 10 and $20 \mathrm{~mm}$, respectively. The Young's modulus $(E)$, bulk modulus $(B)$, shear modulus $(G)$, and Poisson's ratio $(v)$ of the sintered samples were determined by Advanced Ultrasonic Material Characterization System (UMS-100, TECLAB Limited Corp., Changsha, China). Vickers hardness $(H v)$ of the sintered samples was evaluated by Vickers Hardness Tester (HXD-1000TMC\&HVS-30ZG, Tai-Ming Optical Instrument Corp., Shanghai, China) using different test loads from $0.49 \mathrm{~N}(0.05 \mathrm{kgf})$ to $294 \mathrm{~N}$ (30 kgf) and a dwell time of $15 \mathrm{~s}$. For comparing the hardness of HEB and HEB-20SiC ceramics with those of conventional diboride ceramics, $H v$ of $\mathrm{ZrB}_{2}$ single-phase ceramics and $\mathrm{ZrB}_{2}-20$ vol\% $\mathrm{SiC}\left(\mathrm{ZrB}_{2}-20 \mathrm{SiC}\right)$ ceramics were also measured. The R.D. of the $\mathrm{ZrB}_{2}$ and $\mathrm{ZrB}_{2}-20 \mathrm{SiC}$ ceramics is $99.2 \%$ and $99 \%$, respectively. The average grain size of the $\mathrm{ZrB}_{2}$ grains in $\mathrm{ZrB}_{2}$ ceramics is $21.4 \mu \mathrm{m}$. The average grain sizes of the $\mathrm{ZrB}_{2}$ grains and $\mathrm{SiC}$ grains in $\mathrm{ZrB}_{2}-20 \mathrm{SiC}$ ceramics are $2.7 \mu \mathrm{m}$ and $1.65 \mu \mathrm{m}$, respectively. Details of the preparation and the properties of $\mathrm{ZrB}_{2}$ and $\mathrm{ZrB}_{2}-20 \mathrm{SiC}$ ceramics were reported in our previous work $[21,22]$. Fracture toughness $\left(K_{\mathrm{IC}}\right)$ was evaluated by SENB method via three-point bending using a crosshead speed of $0.5 \mathrm{~mm} / \mathrm{min}$ and a span of $16 \mathrm{~mm} \mathrm{[23].} \mathrm{The}$ dimensions of the bars are $2 \mathrm{~mm} \times 4 \mathrm{~mm} \times 25 \mathrm{~mm}$. The notch was prepared by diamond wire cutting with a wire diameter of $80 \mu \mathrm{m}$. The notched width was less than $93 \mu \mathrm{m}$ and the depth was about $1.8-2 \mathrm{~mm}$. The values of the flexural strength and fracture toughness are the average of five measurements, and those of the other mechanical properties are the average of 10 measurements.

\section{Results and discussion}

\section{1 Phase composition and microstructure}

Based on the shrinkage curves of HEB and HEB-20SiC compacts during hot pressing (not shown here), the shrinkage of HEB-20SiC compact finished at about $1750{ }^{\circ} \mathrm{C}$. In contrast, HEB compact stopped shrinking until the sintering temperature reached $1800{ }^{\circ} \mathrm{C}$. The result indicated that the addition of $\mathrm{SiC}$ accelerated the densification process of HEB ceramics which was similar to the case in the SPS process of the same system [5]. After hot pressing, both the received HEB and HEB-20SiC ceramics showed R.D. higher than $99 \%$, indicating full densified ceramics have been prepared by hot pressing in this study. Figure 1 shows the XRD patterns and the SEM morphologies of the hot-pressed ceramics. The main phase in the prepared HEB and HEB-20SiC ceramics is high-entropy diboride of $\left(\mathrm{Ti}_{0.2} \mathrm{Zr}_{0.2} \mathrm{Hf}_{0.2} \mathrm{Nb}_{0.2} \mathrm{Ta}_{0.2}\right) \mathrm{B}_{2}$. Based on the XRD data, the lattice constants of high-entropy phase were calculated to be 3.100(6) $\AA$ and 3.360(4) $\AA$ for $a$ and $c$, respectively. The values are much close to the data ( $a=3.101 \AA, c=3.361 \AA)$ reported by Gild et al. [3]. According to the measured lattice constants, the theoretical densities of HEB and HEB-20SiC ceramics were calculated and listed in Table 1 . The peak intensity for the $\alpha-\mathrm{SiC}$ phase was relatively very low in the HEB-20SiC specimen owing to the weak diffraction compared to that of the diboride phase. In addition, weak diffraction peaks of $(\mathrm{Zr}, \mathrm{Hf}) \mathrm{O}_{2}$ phase were detected attributed to the existence of impurity oxygen in the synthesized $\left(\mathrm{Ti}_{0.2} \mathrm{Zr}_{0.2} \mathrm{Hf}_{0.2} \mathrm{Nb}_{0.2} \mathrm{Ta}_{0.2}\right) \mathrm{B}_{2}$ powder and
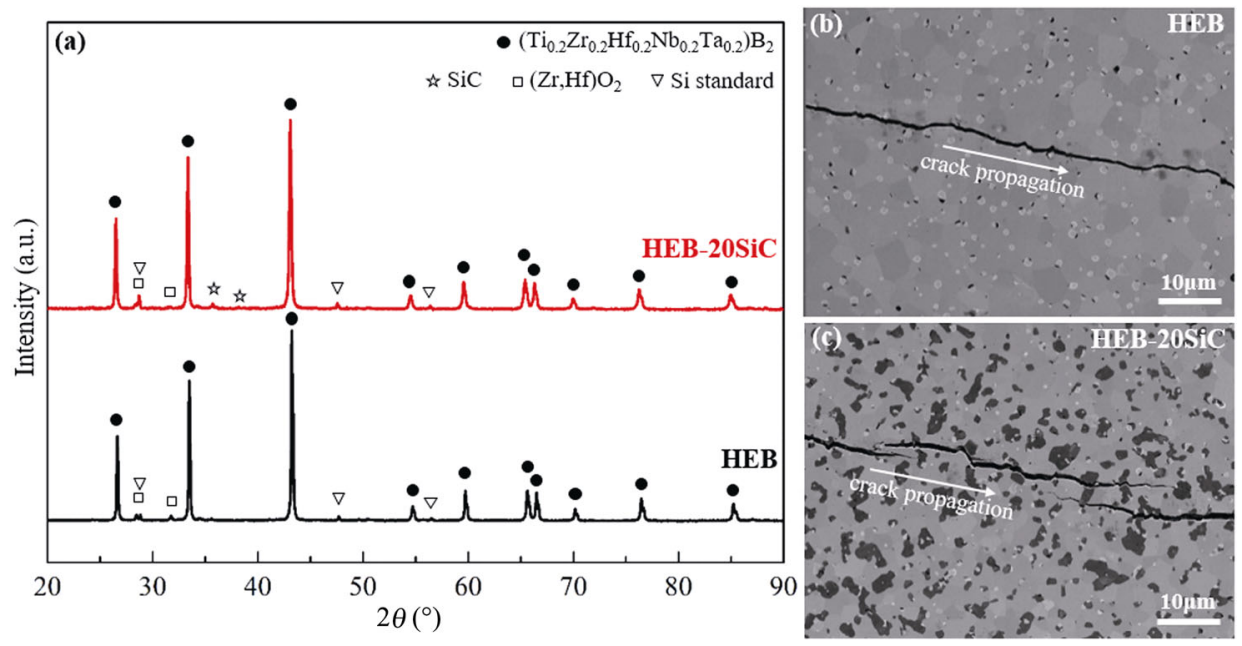

Fig. 1 XRD patterns and SEM morphology of the hot-pressed ceramics. 
Table 1 Properties of the hot-pressed HEB and HEB-20SiC ceramics

\begin{tabular}{lcc}
\hline \multicolumn{1}{c}{ Property } & HEB & HEB-20SiC \\
\hline Theoretical density $\left(\mathrm{g} / \mathrm{cm}^{3}\right)$ & 8.30 & 7.29 \\
Density $(\%)$ & 8.29 & 7.21 \\
Relative density $(\%)$ & 99.8 & 99.0 \\
Average grain size $(\mu \mathrm{m})$ & 4.06 & HEB: 2.70 \\
Young's modulus, $E(\mathrm{GPa})$ & 448 & SiC: 1.51 \\
Bulk modulus, $B(\mathrm{GPa})$ & 233 & 221 \\
Shear modulus, $G(\mathrm{GPa})$ & 190 & 177 \\
Poisson's ratio, $v \quad 0.178$ & 0.185 \\
Hardness, $H v(\mathrm{GPa})$ & & \\
\multicolumn{1}{c}{$H v_{0.2}$} & $23.7 \pm 0.7$ & $24.8 \pm 1.2$ \\
$H v_{1.0}$ & $22.0 \pm 0.9$ & $22.4 \pm 0.7$ \\
$H v_{5.0}$ & $20.2 \pm 0.4$ & $21.4 \pm 0.7$ \\
Fracture toughness, $K_{\mathrm{IC}}\left(\mathrm{MPa} \cdot \mathrm{m}^{1 / 2}\right)$ & $3.81 \pm 0.40$ & $4.85 \pm 0.33$ \\
\hline
\end{tabular}

possible oxygen contamination during the ball milling process as discussed in our previous publication [5].

It can be seen from the SEM image of HEB ceramics showing in Fig. 1(b) that there are some small white particles homogeneously distributed in the grey matrix phase. Combined with the XRD analysis and the following EDS mapping, it can be concluded that the grey matrix is the high-entropy diboride phase and the small white particles are the $(\mathrm{Zr}, \mathrm{Hf}) \mathrm{O}_{2}$ impurity phase. For the HEB-20SiC composite, except the grey high-entropy diboride matrix phase and the small white particles of $(\mathrm{Zr}, \mathrm{Hf}) \mathrm{O}_{2}$ impurity phase, a dark phase identified to the $\mathrm{SiC}$ particles based on the XRD analysis and the following EDS mapping can be clearly seen as shown in Fig. 1(c). Compared to HEB ceramics, HEB-20SiC composite shows finer microstructure. The average grain size of high-entropy diboride matrix phase in HEB-20SiC composite is much smaller than that in HEB ceramics (see Table 1). It is believed that the $\mathrm{SiC}$ particles located at the grain boundaries of the high-entropy diboride matrix phase in the HEB-20SiC composite prevent the motion of grain boundaries by Zener pinning effect during sintering, resulting in an effective inhibition of the grain growth of high-entropy diboride matrix phase and refined the microstructure of the hot pressed ceramics [24].

Figures 2(a) and 2(b) show the element distributions of the hot-pressed HEB and HEB-20SiC ceramics. The transition metal elements of $\mathrm{Ti}, \mathrm{Zr}, \mathrm{Hf}, \mathrm{Nb}$, and $\mathrm{Ta}$ are distributed homogeneously in the prepared ceramics except some $\mathrm{Hf}$ and $\mathrm{Zr}$ segregation combined with impurity oxygen. The element mapping of $\mathrm{Si}, \mathrm{C}$, and $\mathrm{O}$ verified that the dark phase and the white phase are $\mathrm{SiC}$ and impurity oxide, respectively. The quantitative results of EDS analysis are shown in Figs. 2(c) and 2(d). The values are the average of at least five measurements on different positions of the samples. The impurity oxide is mainly consisted of $\mathrm{Hf}, \mathrm{Zr}$, and $\mathrm{O}$ elements, which is $(\mathrm{Zr}, \mathrm{Hf}) \mathrm{O}_{2}$ phase as confirmed by XRD analysis (see Fig. 1). The small peaks for other elements including $\mathrm{B}, \mathrm{Ti}, \mathrm{Nb}, \mathrm{Ta}$ detected in the impurity oxide are considered to be from the background signal of the matrix phase. The existence of $(\mathrm{Zr}, \mathrm{Hf}) \mathrm{O}_{2}$ impurity phase consumes a part of $\mathrm{Hf}$ and $\mathrm{Zr}$ elements, resulting in a slight deviation of the composition from the nominal composition of $\left(\mathrm{Ti}_{0.2} \mathrm{Zr}_{0.2} \mathrm{Hf}_{0.2} \mathrm{Nb}_{0.2} \mathrm{Ta}_{0.2}\right) \mathrm{B}_{2}$ in HEB and HEB-20SiC ceramics.

\section{2 Mechanical properties}

Table 1 lists the mechanical properties of the hot-pressed ceramics. As the Young's modulus of SiC phase (410 GPa [25]) is lower than that of the high-entropy diboride phase, the HEB-20SiC composite shows a decreased Young's modulus. The four-point flexural strength of the composite improved about $32 \%$ when compared to the monolithic. The main contribution of the strength improvement is considered to be the finer grain size of the composite related to the Hall-Petch relationship $\sigma=\sigma_{0}+k D^{-1 / 2}$, where $D$ is the grain size of the material. It can be seen from Fig. 1 and Table 1 that the average grain size of the high-entropy diboride phase is obviously decreased from $4.06 \mu \mathrm{m}$ in the monolithic to $2.70 \mu \mathrm{m}$ in the composite. The fracture toughness of the HEB-20SiC composite increased about $27 \%$ when compared to the monolithic. According to the model proposed by Taya et al. [25], the tensile residual stress in the high-entropy diboride matrix of the composite $(405 \mathrm{MPa}$ in high-entropy diboride phase and $-1619 \mathrm{MPa}$ in $\mathrm{SiC}$ phase) will decrease the toughness by $0.91 \mathrm{MPa} \cdot \mathrm{m}^{1 / 2}$. During the calculation, the following parameters are used: Poisson's ratio for HEB 0.178 (see Table 1) and for $\mathrm{SiC} 0.19$ [25], coefficients of thermal expansion (CTE) for high-entropy diboride phase and SiC phase are respectively $7.815 \times 10^{-6} \mathrm{~K}^{-1}$ (average CTE of five individual diboride along $a$ and $c$ axis from R.T. to $1500{ }^{\circ} \mathrm{C}$ ) [26] and $4.02 \times 10^{-6} \mathrm{~K}^{-1}$ [25], the measured average interparticulate distance of $\mathrm{SiC}$ particles 3.48 $\mu \mathrm{m}$, the thermal stress relieving temperature $1500{ }^{\circ} \mathrm{C}$. Consequently, other toughening mechanism should be 

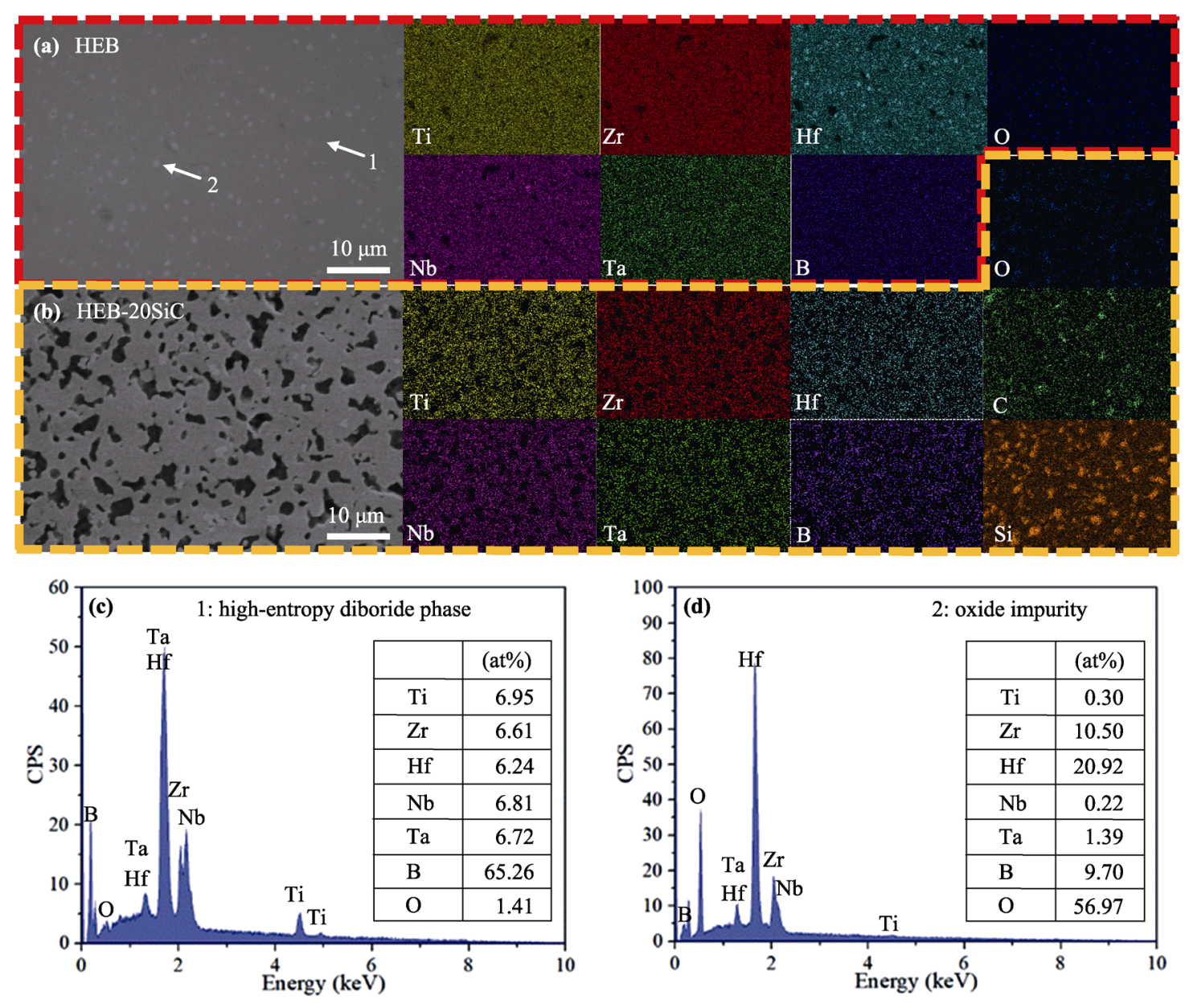

Fig. 2 EDS analysis of the hot-pressed samples. Element mapping of HEB ceramics (a) and HEB-20SiC ceramics (b); the quantitative results of EDS analysis of the high-entropy diboride phase (c) and impurity oxide (d).

considered. The crack propagation paths in HEB monolithic and HEB-20SiC composite during Vickers indentation are shown in Figs. 1(b) and 1(c). It is obvious that the crack propagation in HEB monolithic is flat, but it is tortuous in HEB-20SiC composite due to the crack deflection and branching effect by the $\mathrm{SiC}$ particles. Accordingly, the crack deflection and branching by the $\mathrm{SiC}$ particles is considered to be the main toughening mechanism for HEB-20SiC composite.

As shown in Table 1 , the hardness $H v_{0.2}$ of the hot-pressed HEB ceramics is as high as $23.7 \pm 0.7 \mathrm{GPa}$, which is comparable to the previous reported values in the literature [4]. For comparison, the related $H v_{1.0}$ and $H v_{5.0}$ which are often used for evaluating the hardness of ceramics are also listed in the table. Figure 3(a) shows the Vickers hardness of HEB, HEB-20SiC, $\mathrm{ZrB}_{2}$, and $\mathrm{ZrB}_{2}-20 \mathrm{SiC}$ ceramics under different indentation loads. Compared to the monolithic $\mathrm{ZrB}_{2}$ ceramics with coarse microstructure, the higher hardness in the HEB ceramics should be attributed to both the smaller average grain size and the lattice distortion of high-entropy phase. On the other hand, compared to $\mathrm{ZrB}_{2}-20 \mathrm{SiC}$, HEB-20SiC has similar microstructure but shows higher hardness. The high-entropy $\left(\mathrm{Ti}_{0.2} \mathrm{Zr}_{0.2} \mathrm{Hf}_{0.2} \mathrm{Nb}_{0.2} \mathrm{Ta}_{0.2}\right) \mathrm{B}_{2}$ phase is actually a kind of solid solutions with multi-principal elements. Because both $\mathrm{ZrB}_{2}$ and high-entropy $\left(\mathrm{Ti}_{0.2} \mathrm{Zr}_{0.2} \mathrm{Hf}_{0.2} \mathrm{Nb}_{0.2} \mathrm{Ta}_{0.2}\right) \mathrm{B}_{2}$ have hexagonal crystal structure, the high-entropy $\left(\mathrm{Ti}_{0.2} \mathrm{Zr}_{0.2} \mathrm{Hf}_{0.2} \mathrm{Nb}_{0.2} \mathrm{Ta}_{0.2}\right) \mathrm{B}_{2}$ can be considered as partially substitution of $\mathrm{Zr}$ atoms in the crystal lattice of $\mathrm{ZrB}_{2}$ by Ti, $\mathrm{Hf}, \mathrm{Nb}$, and Ta with different atom radius. This leads to lattice distortion and consequently increases the energy barrier for the motion of dislocations, which can result in the improvement of hardness. Accordingly, the higher hardness of HEB-20SiC over that of the $\mathrm{ZrB}_{2}-20 \mathrm{SiC}$ should be attributed to the lattice distortion in the HEB phase.

It can be obviously seen from Fig. 3(a) that the hardness of the samples changes under different indentation loads. This is caused by the indentation size effect (ISE) which is resulted from the proportional 

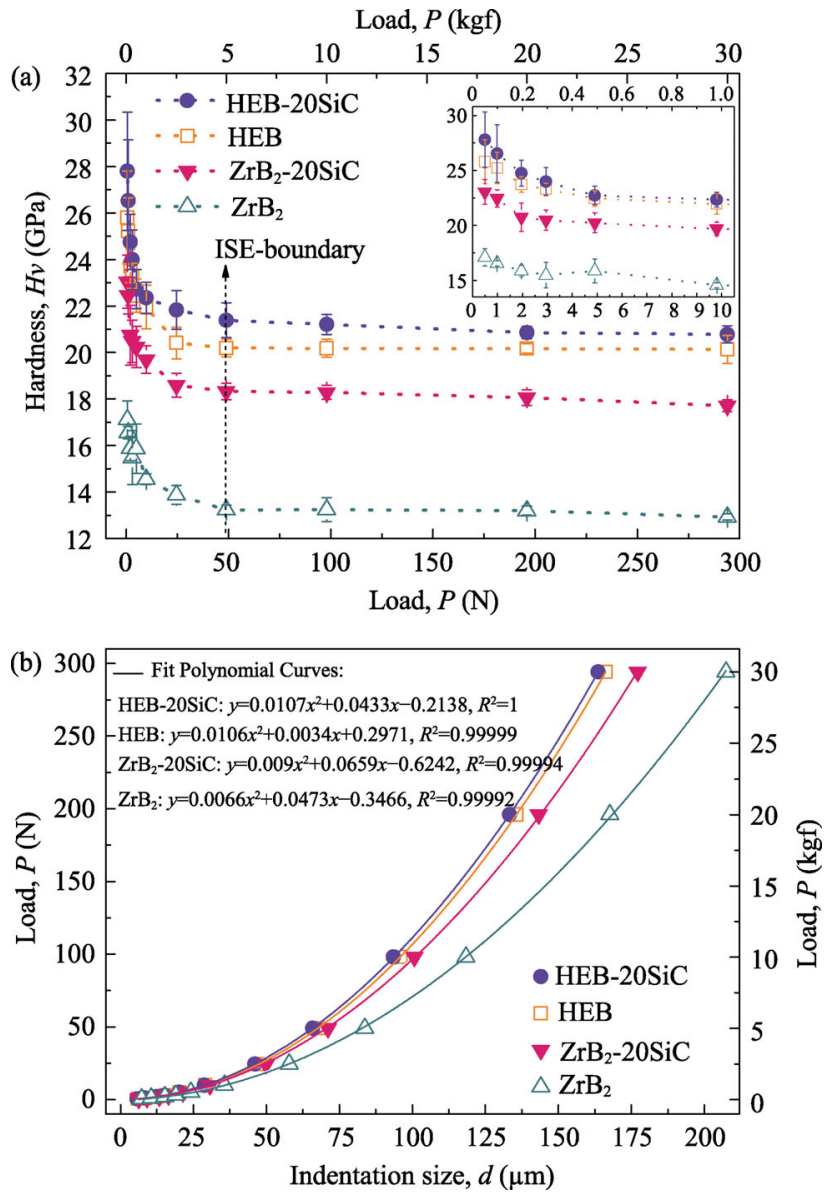

Fig. 3 Vickers hardness of HEB, HEB-20SiC, $\mathrm{ZrB}_{2}$, and $\mathrm{ZrB}_{2}-20 \mathrm{SiC}$ ceramics under different indentation loads: (a) $H v$-load curves; (b) the fit polynomial curves of the load-indentation size relation.

specimen resistance (PSR) [27-30]. With the increasing of indentation loads, the measured hardness decreased fast in the low load range, but gradually reached a stable value at above $49 \mathrm{~N}$. Thus, the indentation load of about $49 \mathrm{~N}$ can be considered as the critical indentation load level $\left(P_{\mathrm{c}}\right)$ and the ISE-boundary for the high-entropy diboride ceramics. Below the ISE-boundary, the ISE contributes obviously to the measured $H v$. Above this boundary, the ISE is significantly reduced and the measured $H v$ will become a constant which can be called as load-independent hardness or "true" hardness $\left(H v_{\text {true }}\right)$ [27]. Based on the PSR model developed by $\mathrm{Li}$ and Bradt [27] and the modified-PSR model proposed by Gong et al. [28], the relationship between the indentation load $(P)$ and the indentation size $(d)$ can be described by the following equation:

$$
P=a_{0}+a_{1} \cdot d+\frac{P_{\mathrm{c}}}{d_{\mathrm{c}}^{2}} \cdot d^{2}
$$

Here, $a_{0}$ relates to the residual surface stresses in the test specimen, $a_{1}$ is the coefficient relating to the PSR, and $d_{\mathrm{c}}$ is the characteristic indentation size. Besides, the relationship among $H v_{\text {true }}, P_{\mathrm{c}}$, and $d_{\mathrm{c}}$ obeys Eq. (2) which is the original formula for the calculation of Vickers hardness of material.

$$
H v_{\text {true }}=1.8544 \cdot \frac{P_{\mathrm{c}}}{d_{\mathrm{c}}^{2}}
$$

Hence, the value of $P_{\mathrm{c}} / d_{\mathrm{c}}^{2}$ and $H v_{\text {true }}$ can be derived from the curve fitting of $P$ and the measured $d$ data. Figure 3(b) shows the fit polynomial $P-d$ curves calculated by using the $d$ data measured in this experiment. The results show that the measured $P-d$ relationship can be perfectly described by the secondorder curves which are completely in accordance with Eq. (1). According to the fit polynomial $P-d$ curves, the value of $H v_{\text {true }}$ is $19.7 \mathrm{GPa}$ for HEB. The calculated values of $H v_{\text {true }}$ are close to the measured $H v_{5.0}(20.2 \pm$ $0.4 \mathrm{GPa}$ for HEB), which also indicates that $49 \mathrm{~N}$ is suitable to be chosen as the ISE-boundary for the high-entropy diboride ceramics.

\section{Conclusions}

In summary, dense $\left(\mathrm{Ti}_{0.2} \mathrm{Zr}_{0.2} \mathrm{Hf}_{0.2} \mathrm{Nb}_{0.2} \mathrm{Ta}_{0.2}\right) \mathrm{B}_{2}$ (HEB) and its composite containing $20 \mathrm{vol} \% \mathrm{SiC}$ (HEB-20SiC) are prepared by hot pressing. The effects of $\mathrm{SiC}$ secondary particles on the densification, microstructure, and mechanical properties of HEB ceramics are investigated. The addition of $\mathrm{SiC}$ not only accelerates the densification process but also refines the microstructure of HEB, resulting in improved mechanical properties. Dense HEB and HEB-20SiC ceramics hot-pressed at $1800{ }^{\circ} \mathrm{C}$ exhibit four-point flexural strength of $339 \pm 17 \mathrm{MPa}$ and $447 \pm 45 \mathrm{MPa}$, and fracture toughness of $3.81 \pm$ $0.40 \mathrm{MPa} \cdot \mathrm{m}^{1 / 2}$ and $4.85 \pm 0.33 \mathrm{MPa} \cdot \mathrm{m}^{1 / 2}$, respectively. Such values of room temperature bending strength and fracture toughness are typical of structure ceramics. Crack deflection and branching by $\mathrm{SiC}$ particles is considered to be the main toughening mechanisms for the HEB-20SiC composite. The hardness $H v_{0.2}$ of the sintered HEB and HEB-20SiC ceramics is $23.7 \pm$ $0.7 \mathrm{GPa}$ and $24.8 \pm 1.2 \mathrm{GPa}$, respectively. With the increase of indentation load, the hardness of the sintered ceramics decreases rapidly until the load reaches about $49 \mathrm{~N}$, due to the indentation size effect. 


\section{Acknowledgements}

This work was supported by the National Natural Science Foundation of China (Nos. 51532009, 51872045); Science and Technology Commission of Shanghai Municipality (No. 18ZR1401400); the Fundamental Research Funds for the Central Universities (Nos. 2232018D3-32, 2232019A3-13); and State Key Laboratory for Modification of Chemical Fibers and Polymer Materials, Donghua University (No. 19ZK0113).

\section{References}

[1] Yeh JW, Chen SK, Lin SJ, et al. Nanostructured high-entropy alloys with multiple principal elements: Novel alloy design concepts and outcomes. Adv Eng Mater 2004, 6: 299-303.

[2] George EP, Raabe D, Ritchie RO. High-entropy alloys. Nat Rev Mater 2019, 4: 515-534.

[3] Gild J, Zhang YY, Harrington T, et al. High-entropy metal diborides: A new class of high-entropy materials and a new type of ultrahigh temperature ceramics. Sci Rep 2016, 6: 37946-37956.

[4] Zhang Y, Jiang ZB, Sun SK, et al. Microstructure and mechanical properties of high-entropy borides derived from boro/carbothermal reduction. J Eur Ceram Soc 2019, 39: 3920-3924.

[5] Shen XQ, Liu JX, Li F, et al. Preparation and characterization of diboride-based high entropy $\left(\mathrm{Ti}_{0.2} \mathrm{Zr}_{0.2} \mathrm{Hf}_{0.2} \mathrm{Nb}_{0.2} \mathrm{Ta}_{0.2}\right) \mathrm{B}_{2}-\mathrm{SiC}$ particulate composites. Ceram Int 2019, 45: 24508-24514.

[6] Gu JF, Zou J, Sun SK, et al. Dense and pure high-entropy metal diboride ceramics sintered from self-synthesized powders via boro/carbothermal reduction approach. Sci China Mater 2019, 62: 1898-1909.

[7] Failla S, Galizia P, Fu S, et al. Formation of high entropy metal diborides using arc-melting and combinatorial approach to study quinary and quaternary solid solutions. $J$ Eur Ceram Soc 2020, 40: 588-593.

[8] Chen H, Xiang HM, Dai FZ, et al. Porous high entropy $\left(\mathrm{Zr}_{0.2} \mathrm{Hf}_{0.2} \mathrm{Ti}_{0.2} \mathrm{Nb}_{0.2} \mathrm{Ta}_{0.2}\right) \mathrm{B}_{2}$ : A novel strategy towards making ultrahigh temperature ceramics thermal insulating. J Mater Sci Tech 2019, 35: 2404-2408.

[9] Sarker P, Harrington T, Toher C, et al. High-entropy high-hardness metal carbides discovered by entropy descriptors. Nat Commun 2018, 9: 4980.

[10] Castle E, Csanádi T, Grasso S, et al. Processing and properties of high-entropy ultra-high temperature carbides. Sci Rep 2018, 8: 8609.

[11] Wei XF, Liu JX, Li F, et al. High entropy carbide ceramics from different starting materials. J Eur Ceram Soc 2019, 39: 2989-2994.

[12] Lu K, Liu JX, Wei XF, et al. Microstructures and mechanical properties of high-entropy $\left(\mathrm{Ti}_{0.2} \mathrm{Zr}_{0.2} \mathrm{Hf}_{0.2^{-}}\right.$ $\left.\mathrm{Nb}_{0.2} \mathrm{Ta}_{0.2}\right) \mathrm{C}$ ceramics with the addition of SiC secondary phase. J Eur Ceram Soc 2020, 40: 1839-1847.

[13] Rost CM, Sachet E, Borman T, et al. Entropy-stabilized oxides. Nat Commun 2015, 6: 8485.

[14] Jiang SC, Hu T, Gild J, et al. A new class of high-entropy perovskite oxides. Scripta Mater 2018, 142: 116-120.

[15] Li F, Zhou L, Liu JX, et al. High-entropy pyrochlores with low thermal conductivity for thermal barrier coating materials. $J$ Adv Ceram 2019, 8: 576-582.

[16] Dong Y, Ren K, Lu YH, et al. High-entropy environmental barrier coating for the ceramic matrix composites. $J$ Eur Ceram Soc 2019, 39: 2574-2579.

[17] Qin Y, Liu JX, Li F, et al. A high entropy silicide by reactive spark plasma sintering. $J$ Adv Ceram 2019, 8: $148-152$.

[18] Gild J, Braun J, Kaufmann K, et al. A high-entropy silicide: $\left(\mathrm{Mo}_{0.2} \mathrm{Nb}_{0.2} \mathrm{Ta}_{0.2} \mathrm{Ti}_{0.2} \mathrm{~W}_{0.2}\right) \mathrm{Si}_{2}$. J Materiomics 2019, 5: 337-343.

[19] Chen XQ, Wu YQ. High-entropy transparent fluoride laser ceramics. J Am Ceram Soc 2020, 103: 750-756.

[20] Li F, Bao WC, Sun SK, et al. Synthesis of single-phase metal oxycarbonitride ceramics. Scripta Mater 2020, 176: 17-22.

[21] Ma HB, Man ZY, Liu JX, et al. Microstructures, solid solution formation and high-temperature mechanical properties of $\mathrm{ZrB}_{2}$ ceramics doped with 5vol.\% WC. Mater Design 2015, 81: 133-140.

[22] Zou J, Zhang GJ, Zhang $\mathrm{H}$, et al. Improving high temperature properties of hot pressed $\mathrm{ZrB}_{2}-20 \mathrm{vol} \% \mathrm{SiC}$ ceramic using high purity powders. Ceram Int 2013, 39: 871-876.

[23] Zhang GJ, Jin ZZ, Yue XM. TiN-TiB 2 composites prepared by reactive hot pressing and effects of Ni addition. $J \mathrm{Am}$ Ceram Soc 1995, 78: 2831-2833.

[24] Smith CS. Introduction to grains, phases, and interfacesAn interpretation of microstructure. Trans AIME 1948, 175: $15-51$.

[25] Taya M, Hayashi S, Kobayashi AS, et al. Toughening of a particulate-reinforced ceramic-matrix composite by thermal residual stress. J Am Ceram Soc 1990, 73: 1382-1391.

[26] Keihn FG, Keplin EJ. High-temperature thermal expansion of certain group IV and group V diborides. J Am Ceram Soc 1967, 50: 81-84.

[27] Li H, Bradt RC. The microhardness indentation load/size effect in rutile and cassiterite single crystals. J Mater Sci 1993, 28: 917-926.

[28] Gong JH, Wu JJ, Guan ZD. Examination of the indentation 
size effect in low-load Vickers hardness testing of ceramics. J Eur Ceram Soc 1999, 19: 2625-2631.

[29] Jiang DY. Recent progresses in the phenomenological description for the indentation size effect in microhardness testing of brittle ceramics. J Adv Ceram 2012, 1: 38-49.

[30] Duan YB, Jiang DY, Hu J. Determination of the load-independent hardness by analyzing the nanoindentation loading curves: A case study on fused silica. $J$ Adv Ceram 2019, 8: 583-586.

Open Access This article is licensed under a Creative Commons Attribution 4.0 International License, which permits use, sharing, adaptation, distribution and reproduction in any medium or format, as long as you give appropriate credit to the original author(s) and the source, provide a link to the Creative Commons licence, and indicate if changes were made.

The images or other third party material in this article are included in the article's Creative Commons licence, unless indicated otherwise in a credit line to the material. If material is not included in the article's Creative Commons licence and your intended use is not permitted by statutory regulation or exceeds the permitted use, you will need to obtain permission directly from the copyright holder.

To view a copy of this licence, visit http://creativecommons.org/licenses/by/4.0/. 